\title{
Multilayer Adsorption of Heptane Vapor at Water Drop Surfaces
}

\author{
Volodymyr I. Kovalchuk ${ }^{1}$, Eugene V. Aksenenko ${ }^{2}$, Valentin B. Fainerman ${ }^{3}$, Aliyar Javadi ${ }^{4,5}$ and \\ Reinhard Miller ${ }^{4, *}$ \\ 1 Institute of Biocolloid Chemistry, 03680 Kyiv (Kiev), Ukraine; Volodja.Kovalchuk@mpikg.mpg.de \\ 2 Institute of Colloid Chemistry and Chemistry of Water, 03680 Kyiv (Kiev), Ukraine; \\ Eugene_Aksenenko@ukr.net \\ 3 SINTERFACE Technologies, 12489 Berlin, Germany; fainerman@dkt.dn.ua \\ 4 Max-Planck Institute of Colloids and Interfaces, 14476 Potsdam, Germany; javadi.aliyar@ut.ac.ir \\ 5 Institute of Petroleum Engineering, University of Tehran, 14174-66191 Tehran, Iran \\ * Correspondence: Reinhard.Miller@mpikg.mpg.de; Tel.: +49-331-925-9252
}

Received: 16 November 2017; Accepted: 1 December 2017; Published: 4 December 2017

\begin{abstract}
The measured dynamic surface tension of a water drop in air saturated by heptane vapor shows a sharp decrease from about $60 \mathrm{mN} \mathrm{m}^{-1}$ to $40 \mathrm{mN} \mathrm{m}^{-1}$, and less after a certain adsorption time. The observed adsorption kinetics is analyzed by a theoretical model based on multilayer adsorption of alkanes from the vapor phase at the water surface. The model assumes a dependence of the kinetic coefficients of adsorption and desorption on the surface coverage and in equilibrium it reduces to the classical Brunauer-Emmett-Teller adsorption isotherm. The calculated time dependencies of adsorption and surface tension agree well with experimental data and predict a five-layer adsorption of heptane.
\end{abstract}

Keywords: heptane adsorption from vapor phase; drop profile analysis tensiometry; adsorption kinetics model; multilayer adsorption

\section{Introduction}

Various experimental and theoretical studies of adsorption of alkanes from the gas phase on a water surface were previously reported [1-17]. The thickness of such adsorbed alkane layers was determined with optical methods being maximum up to $4-5 \mathrm{~nm}$ [6]. This indicates the formation of a bulk alkane phase at the water surface, and that the surface tension of this phase to air should be close to that of the pure alkane/water interface. The increase of the thickness is an extremely slow process: it needs $200 \mathrm{~h}$ to attain this value. For the adsorption process during $10 \mathrm{~h}$ the layer thickness for heptane was about $1.5 \mathrm{~nm}$.

During last years, a large pool of experimental data was collected, and theoretical models were developed for the adsorption of alkanes from the gas phase on the surface of a water drop [7-17]. It was shown, for instance, that the adsorption of alkanes from the gas phase results in a significant decrease of the surface tension of water or aqueous protein (surfactant) solutions. Moreover, measurements and analysis of tensiometric data [7] demonstrated that the adsorption of alkanes on the surface of water drops can lead to a condensation of the alkane molecules at the surface and to the formation of liquid films. It was shown [12] that the influence of hexane vapor on the surface tension of water depends also essentially on the air humidity. The dynamic surface tension dependencies for drops of aqueous $\mathrm{C}_{14} \mathrm{EO}_{8}$ solutions at the interface to air saturated by pentane, hexane, heptane and toluene, respectively, and for drops of water at these interfaces were discussed [17]. The experimental results were well described by a model which implies a diffusion processes for the $\mathrm{C}_{14} \mathrm{EO}_{8}$ molecules and the existence of a kinetic barrier for the alkane molecules. The desorption process was shown to be 
slow for heptane and hexane, however, for pentane vapor the desorption was quite rapid, and after the desorption commences the surface tension became equal to that at the interface with pure air.

In [18], the influence of temperature (in the range of $20-50^{\circ} \mathrm{C}$ ) on the dynamic surface tension of water (as measured by drop profile analysis tensiometry) in heptane and pentane vapors was studied, and it was shown that at long times of drop ageing in heptane vapor, a sharp decrease of surface tension (from $55-60 \mathrm{mN} \mathrm{m}^{-1}$ to $30-40 \mathrm{mN} \mathrm{m}^{-1}$ ) occurred. The time at which this sharp decrease started became lower with increasing temperature: $10,000-15,000 \mathrm{~s}$ at $20^{\circ} \mathrm{C}$, and $500-700 \mathrm{~s}$ at $50{ }^{\circ} \mathrm{C}$. This phenomenon was attributed to the formation of heptane adsorption layers with significant thicknesses. The sharp surface tension decrease was observed with errors in fitting the drop profile coordinates being below $5 \mu \mathrm{m}$. Therefore, this phenomenon of a sharp surface tension decrease caused by the formation of polylayers does really exist.

Our previous studies $[17,18]$ have shown that the rate of alkane adsorption at an aqueous surface is not limited by diffusion of alkane molecules in a gas (vapor) phase but has a kinetic limitation due to an energy barrier for adsorbing/desorbing molecules. Such a process can be described in terms of kinetic equations. A set of kinetic equations was proposed and applied to analyze experimental data. However, the formation of only two alkane adsorption layers was assumed [17,18], whereas the experimental data show that the adsorption films of alkanes at an aqueous solution surface should consist of more than one or two adsorption layers. At later stages of the process one can even observe a transition from adsorption to condensation. Therefore, a more general model is required, which would account for multilayer alkane films formed by adsorption from the vapor phase.

In the present study, we formulated a kinetic model for the formation of multilayer alkane films, which also takes into account such effects as interaction among alkane molecules in the layers and variation of the molar area of alkane molecules with increasing surface tension. The model describes the variation of the measured surface tension with time and constrains the model parameters, in particular, the kinetic coefficients.

\section{Theory}

The kinetics of formation of a multilayer adsorption film can be described by a set of equations dedicated to the first layer:

$$
\frac{\mathrm{d} \Gamma_{1}}{\mathrm{dt}}=\beta_{1} \mathrm{c}\left(1-\Gamma_{1} \omega_{1}\right)-\alpha_{1}\left(\Gamma_{1} \omega_{1}-\Gamma_{2} \omega_{2}\right),(j=1)
$$

and for the subsequent layers:

$$
\frac{\mathrm{d} \Gamma_{\mathrm{j}}}{\mathrm{dt}}=\beta_{\mathrm{j}} \mathrm{c}\left(\Gamma_{\mathrm{j}-1} \omega_{\mathrm{j}-1}-\Gamma_{\mathrm{j}} \omega_{\mathrm{j}}\right)-\alpha_{\mathrm{j}}\left(\Gamma_{\mathrm{j}} \omega_{\mathrm{j}}-\Gamma_{\mathrm{j}+1} \omega_{\mathrm{j}+1}\right),(\mathrm{j} \geq 2)
$$

Here, $c$ is the concentration of alkane in the ambient gas phase, $\Gamma_{j}=N_{j} / S$ is the alkane adsorption in the $j$-th layer, $N_{j}$ is the number of alkane molecules within the layer, $S$ is the total surface area, $\omega_{j}$ is the molar area of alkane molecule in the $j$-th layer, and $\beta_{j}$ and $\alpha_{j}$ are the kinetic coefficients for the adsorption and desorption process, respectively, in the first and subsequent layers. The formalism involved in Equations (1) and (2) is illustrated schematically by Figure 1. In Equation (2), the adsorption terms are proportional to the factors $\left(\Gamma_{j-1} \omega_{j-1}-\Gamma_{j} \omega_{j}\right)$, because the adsorption in the $j$-th layer is possible on the part of the surface which is already covered by the previous layer but is not covered yet by the considered layer, while, in Equation (1), the term $\left(1-\Gamma_{1} \omega_{1}\right)$ corresponds to the adsorption within the first layer. Similarly, the desorption terms are proportional to the factors $\left(\Gamma_{j} \omega_{j}-\Gamma_{j+1} \omega_{j+1}\right)$, which means the desorption from the j-th layer can occur on the part of the surface already covered by this layer but not blocked yet from the top by the subsequent layer, because the molecules from the subsequent layer prevent desorption from the previous layer. The kinetic equation for the $j$-th layer, Equation (2), reduces to the standard Langmuir kinetics equation in the particular case when the molecules of the previous layer cover the whole surface $\left(\Gamma_{j-1} \omega_{j-1}=1\right)$ and the subsequent layer has 
not begun to form yet $\left(\Gamma_{j+1} \omega_{j+1}=0\right)$. Note that, in the formulation above, it is assumed that the molar area of the adsorbed alkane molecule can be different in different layers; this will allow involving the intrinsic compressibility of the adsorbed molecules, as shown below.

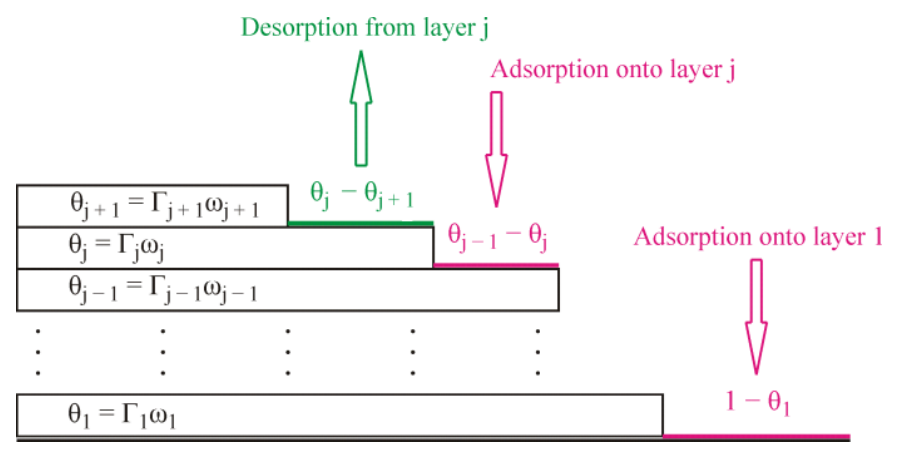

Figure 1. Schematic of adsorption in a multilayer system. The horizontal bars correspond to the fraction of total surface area covered by molecules in the $\mathrm{j}$-th layer, while the arrows correspond to the adsorption onto and the desorption from a layer. Note that the total surface coverage corresponds to $\theta=1$.

The set of kinetic equations given by Equations (1) and (2) assumes that the main relaxation process is the barrier-limited exchange of molecules with the bulk (vapor) phase, because the diffusion of the gas molecules is very fast $[17,18]$. This means that rearrangements within the adsorbed multilayer film are also very quick, much quicker than the kinetics of adsorption on the top of the film from outside.

Under equilibrium conditions, the time derivatives in the left hand sides of Equations (1) and (2) are zero. The solution of the resulting set of algebraic equations yields the equilibrium adsorptions $\Gamma_{j}^{\mathrm{eq}}$ in each layer. One usually assumes the kinetic coefficients to be constants and to be the same for the second and subsequent layers: $\beta_{j}=\beta$ and $\alpha_{j}=\alpha$ for $j \geq 2$; also the molar areas in all layers are assumed to be the same and equal to $\omega$. In this particular case the equilibrium adsorptions in the layers can be obtained as:

$$
\begin{gathered}
\Gamma_{1}^{\mathrm{eq}}=\frac{1}{\omega} \cdot \frac{\mathrm{x}_{1}}{1-\mathrm{x}+\mathrm{x}_{1}} \\
\Gamma_{\mathrm{j}}^{\mathrm{eq}}=\frac{\mathrm{x}^{\mathrm{j}-1}}{\omega} \cdot \frac{\mathrm{x}_{1}}{1-\mathrm{x}+\mathrm{x}_{1}},(\mathrm{j} \geq 2)
\end{gathered}
$$

where $x_{1}=\left(\beta_{1} / \alpha_{1}\right) c=b_{1} c_{A}, x=(\beta / \alpha) c=b_{2} c$ with $b_{1}=\beta_{1} / \alpha_{1}$ and $b_{2}=\beta / \alpha$ being the equilibrium adsorption constants for the first and subsequent layers, respectively. Then, the total adsorption $\Gamma_{\Sigma}^{\mathrm{eq}}=\sum_{\mathrm{j}} \Gamma_{\mathrm{j}}^{\mathrm{eq}}$ can be obtained as:

$$
\Gamma_{\Sigma}^{\mathrm{eq}}=\frac{1}{\omega(1-\mathrm{x})} \cdot \frac{\mathrm{x}_{1}}{1-\mathrm{x}+\mathrm{x}_{1}}=\frac{\mathrm{Kx}}{\omega(1-\mathrm{x})(1-\mathrm{x}+\mathrm{Kx})}
$$

with $\mathrm{K}=\left(\beta_{1} / \alpha_{1}\right) \cdot(\alpha / \beta)$. Equation (5) is just the multilayer adsorption isotherm which follows from the classical Brunauer-Emmett-Teller (BET) theory [19]. It should be noted, however, that, unlike the case of adsorption on a solid surface, we do not assume here that the molecules adsorb on fixed adsorption sites.

It is important that the alkane molecules adsorbed at an aqueous solution surface are mobile. They freely move over the available space at the surface. The molecules in the next layer freely move over the molecules which form the previous one. If we imagine a momentary picture of the adsorbed molecules, we will see something like patches consisting of different numbers of adsorption layers in different places and the molecules randomly distributed within the layers. The simplified schematic shown in Figure 1 does not reflect this peculiarity. The lifetime of these patches is very short, and they should change continuously, as the adsorbed molecules proceed to move. Thus, we 
can only speak about a probability to have certain amounts of molecules in each layer in a certain time moment. Under equilibrium conditions these amounts should not change. However, such a dynamic equilibrium implies a continuous exchange of the molecules between the different layers and between the surface and the bulk (vapor) phase. Under non-equilibrium conditions, i.e., when adsorption process proceeds, the amount of the molecules in each layer increases with time. Similar to the classical Langmuir and Frumkin isotherms, which are applicable for the case of non-localized adsorption at liquid interfaces [20], we assume that our model can be applied to the case of multilayer adsorption from a vapor phase at liquid interfaces.

The model considered here assumes that the adsorbed alkane molecules are ordered in parallel layers. Such approximation is possible only when we have a small number of adsorption layers, probably up to 3-5 [18]. For a larger number of layers, the molecules will not be fixed within the strictly parallel layers, but the layers will rather mix, and the system will resemble rather something more similar to a bulk phase of alkane with disordered molecules, i.e., a condensed film. The applicability of the model should be limited in this case, and restricted to the initial stage of the process, when the number of adsorption layers is sufficiently small.

To take into account the interaction among alkane molecules in the layers we assume, similarly to the Frumkin theory, that the kinetic coefficients $\beta_{j}$ and $\alpha_{j}$ in Equations (1) and (2) depend on the surface coverage:

$$
\beta_{j}=\beta_{j, 0} \exp \left(-\varphi_{a, j} \theta_{j}\right), \alpha_{j}=\alpha_{j, 0} \exp \left(-\varphi_{d, j} \theta_{j}\right)
$$

where $\beta_{j, 0}, \alpha_{j, 0}, \varphi_{a, j}$ and $\varphi_{d, j}$ are model parameters, and $\theta_{j}=\Gamma_{j} \omega_{j}$ is the surface coverage in the j-th layer. In line with the adopted BET-like approach, we assume that the values $\varphi_{\mathrm{a}, \mathrm{j}}$ and $\varphi_{\mathrm{d}, \mathrm{j}}$, and the parameters $\beta_{\mathrm{j}, 0}$ and $\alpha_{\mathrm{j}, 0}$ for the second to the subsequent layers do not change, thus reducing the number of model parameters to eight: $\beta_{1,0}, \beta_{2,0}, \alpha_{1,0}, \alpha_{2,0}, \varphi_{\mathrm{a}, 1}, \varphi_{\mathrm{d}, 1}, \varphi_{\mathrm{a}, 2}$ and $\varphi_{\mathrm{d}, 2}$, where the subscript 2 refers to the second and further layers. In this case, when the interaction between alkane molecules within the layer is assumed to exist, the equilibrium state cannot be described by the simple Equations (3)-(5), but obeys a more complicated set of transcendent equations which would have to be solved numerically.

At the initial stage the adsorption film only consists of several alkane layers. Therefore, for the numerical solution, only a limited number of layers L should be accounted for, while the contribution of the layers with $\mathrm{j}>\mathrm{L}$ is neglected. Then, in terms of surface coverages, the set of kinetic equations becomes:

$$
\begin{gathered}
\frac{1}{\omega_{1}} \frac{\mathrm{d} \theta_{1}}{\mathrm{dt}}=\beta_{1} \mathrm{c}\left(1-\theta_{1}\right)-\alpha_{1}\left(\theta_{1}-\theta_{2}\right)(\mathrm{j}=1) \\
\frac{1}{\omega_{j}} \frac{\mathrm{d} \theta_{\mathrm{j}}}{\mathrm{dt}}=\beta_{\mathrm{j}} \mathrm{c}\left(\theta_{\mathrm{j}-1}-\theta_{\mathrm{j}}\right)-\alpha_{\mathrm{j}}\left(\theta_{\mathrm{j}}-\theta_{\mathrm{j}+1}\right)(2 \leq \mathrm{j}<\mathrm{L}) \\
\frac{1}{\omega_{\mathrm{L}}} \frac{\mathrm{d} \theta_{\mathrm{L}}}{\mathrm{dt}}=\beta_{\mathrm{L}} \mathrm{c}\left(\theta_{\mathrm{L}-1}-\theta_{\mathrm{L}}\right)-\alpha_{\mathrm{L}} \theta_{\mathrm{L}}(\mathrm{j}=\mathrm{L})
\end{gathered}
$$

where the kinetic coefficients $\beta_{j}$ and $\alpha_{j}$ as functions of $\theta_{j}$ are given by Equation (6).

The model also allows for a possible variation of the tilt angle of the alkyl chains (alkane molecules) in the layers depending on the surface pressure [21]. This variation of the tilt angle results in a variation of the molar area of alkane molecules, therefore we will consider the molar area $\omega_{\mathrm{j}}$ in Equations (7)-(9) to depend on the surface pressure per $\mathrm{j}$-th layer $\Pi_{\mathrm{j}}$ :

$$
\omega_{\mathrm{j}}=\omega_{0}\left(1-\varepsilon \Pi_{\mathrm{j}}\right)
$$


where $\varepsilon$ is the intrinsic compressibility coefficient, and $\omega_{0}$ is the molar area at the very initial stage of the surface coverage, and, similar to [17,18]:

$$
\begin{gathered}
\Pi_{1}=-\frac{R T}{\omega_{1}}\left[\ln \left(1-\theta_{1}\right)+a_{1} \theta_{1}^{2}\right] \\
\Pi_{j}=-\frac{R T}{\omega_{j}}\left[\ln \left(1-\theta_{j} \theta_{j-1}\right)+a_{2} \theta_{j}^{2}\right](2 \leq \mathrm{j} \leq \mathrm{L})
\end{gathered}
$$

where $\mathrm{a}_{\mathrm{i}}=\left(\varphi_{\mathrm{d}, \mathrm{i}}-\varphi_{\mathrm{a}, \mathrm{i}}\right) / 2$ are the Frumkin interaction parameters $(\mathrm{i}=1,2)$, and the total surface pressure is calculated as the sum across the first $L$ layers:

$$
\Pi=\sum_{\mathrm{j}=1}^{\mathrm{L}} \Pi_{\mathrm{j}}
$$

Then, the surface tension is calculated as

$$
\gamma=\gamma_{0}-\Pi
$$

where $\gamma_{0}$ is the surface tension of the pure solvent (water). Equations (11) and (12) assume a quasi-equilibrium state of the adsorption film, which is determined by the set of surface coverages varying slowly with time: $\theta_{j}=\theta_{j}(t)$ according to Equations (6)-(9). Thus, to describe the multilayer adsorption process, we have to solve numerically the set of ordinary differential Equations (Equations (7)-(9)), taking into account the additional Equations (Equations (6), and (10)-(13)). The calculation algorithm used for the solution is described in some detail in the Appendix A.

\section{Results and Discussion}

The calculations according to the proposed model were compared with the results obtained in [18] for the surface tension measured for water drops in air saturated by heptane vapor. Figure 2a,b illustrates the experimental results reported in [18] and the kinetic curves calculated from the multilayer adsorption model explained above. In the calculations, the number of layers was assumed to be 5 , which in the limit of maximum times used in the experiments (from $50,000 \mathrm{~s}$ at $20{ }^{\circ} \mathrm{C}$ to $5000 \mathrm{~s}$ at $50{ }^{\circ} \mathrm{C}$ ) corresponds to an increase of the adsorbed amount by several times as compared to a monolayer adsorption. It is seen from the experimental data that at the initial stage of adsorption the surface tension exhibits a rapid decrease down to approximately $60 \mathrm{mN} \mathrm{m}^{-1}$ (first characteristic point shown for $20^{\circ} \mathrm{C}$ data at $1400 \mathrm{~s}$ by arrow). Subsequently, the surface tension remains almost constant until the second characteristic point at 15,000 s, followed by a sharp decrease.

The location of these characteristic points is different for different temperatures. For example, at $50{ }^{\circ} \mathrm{C}$ these points are located at 100 and $350 \mathrm{~s}$. It follows from the model that at times shorter than the second characteristic point the formation of monolayers occurs, while at longer times we expect multilayers to be formed. In our earlier publication [18] monolayer adsorption was assumed: in the "post-critical" range (above the second characteristic point), we made approximate estimations only, and we found agreement between the experimental values and theoretical predictions only when the molar area was reduced by a factor of 3 . However, such an assumption yields adsorption values by a factor of 3-4 higher than that following from the present model at surface tensions between 40 to $30 \mathrm{mN} \mathrm{m}^{-1}$. It is seen in Figure $2 \mathrm{a}, \mathrm{b}$ that the curves calculated using the proposed model agree reasonably well with the experiments.

Please note, the main driving force for the alkane adsorption in all layers is the adsorption energy, which can be quantified by the decrease in surface tension per layer. This value is highest for the first layer (alkane adsorption at the water surface), and it is less for the second and subsequent layers. For a large number of layers (say, larger than 5), this energy is very small, but, since there is some decrease 
in tension, an increase in the number of layers to 10 appears possible, however, this would be a very slow process [6].

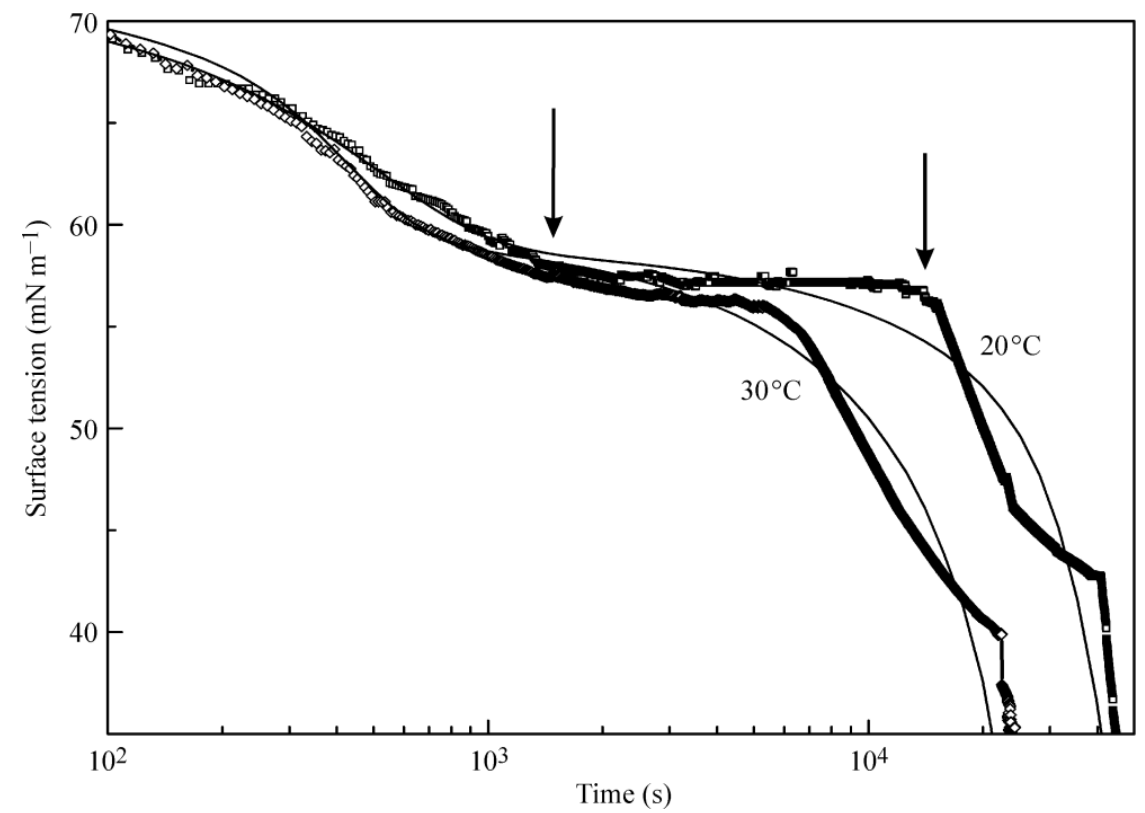

(a)

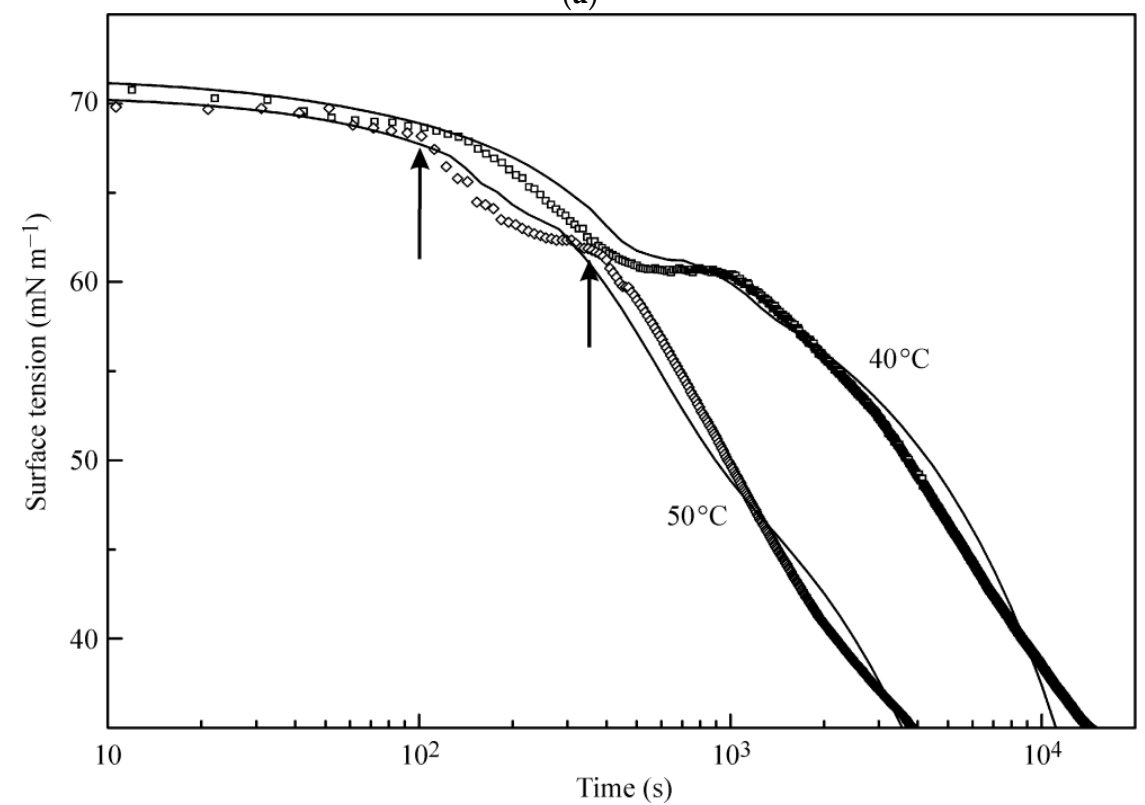

(b)

Figure 2. Dynamic surface tension at water drops in air saturated by heptane vapor at different temperatures: 20 and $30{ }^{\circ} \mathrm{C}(\mathbf{a})$; and 40 and $50{ }^{\circ} \mathrm{C}(\mathbf{b})$. Points, experimental data; curves, theoretical calculations assuming five layers, and values of parameters listed in Table 1. Arrows indicate the positions of characteristic points. For detailed explanation, see text.

It is seen in Table 1 that $\beta_{1,0}$ (first layer) is larger than $\beta_{2,0}$ (second and subsequent layers). With increasing temperature, this difference becomes less pronounced: from two orders of magnitude at $20{ }^{\circ} \mathrm{C}$ to one order of magnitude at $50{ }^{\circ} \mathrm{C}$. At the same time, the parameter $\beta_{1,0}$ becomes lower, while the product $\beta_{1,0} \times c$ remains approximately constant, i.e., the heptane adsorption rate in the first layer is independent of temperature. On the contrary, for the second and further layers, both the $\beta_{2,0}$ value and the $\beta_{2,0} \times c$ product in general increase with temperature: the product value becomes higher at 
$50{ }^{\circ} \mathrm{C}$ by one order of magnitude as compared with its value at $20^{\circ} \mathrm{C}$. In addition, $\mathrm{d}_{2}$ is essentially higher than $\mathrm{d}_{1}$ (as shown in Table 1 after and before the slash ("/"), respectively). It should be noted that the number of layers assumed in the calculations influences not only the adsorbed amount, but also the surface tension. In particular, at $30^{\circ} \mathrm{C}$, for a five-layer adsorption, it takes $28,000 \mathrm{~s}$ to decrease the surface tension value down to $30 \mathrm{mN} \mathrm{m}^{-1}$, while, for a two-layer adsorption, the required time is as high as $40,000 \mathrm{~s}$.

Table 1. Model parameters of heptane adsorption at different temperatures. Note, instead of four model parameters $\varphi_{\mathrm{a}, \mathrm{i}}$ and $\varphi_{\mathrm{d}, \mathrm{i}}(\mathrm{i}=1,2)$, the parameters $\mathrm{a}_{\mathrm{i}}=\left(\varphi_{\mathrm{d}, \mathrm{i}}-\varphi_{\mathrm{a}, \mathrm{i}}\right) / 2$ and $\mathrm{d}_{\mathrm{i}}=\left(\varphi_{\mathrm{d}, \mathrm{i}}+\varphi_{\mathrm{a}, \mathrm{i}}\right) / 2$ are used in the calculations.

\begin{tabular}{|c|c|c|c|c|c|c|c|c|c|}
\hline $\begin{array}{l}\text { Temperature, } \\
{ }^{\circ} \mathrm{C}\end{array}$ & $\begin{array}{c}\mathbf{c}, \\
\mathrm{mol} \mathrm{m}^{-3}\end{array}$ & $\begin{array}{c}\omega, \\
10^{5} \mathrm{~m}^{2} \mathrm{~mol}^{-1}\end{array}$ & $\begin{array}{c}\beta_{1,0} \\
10^{-9} \mathrm{~m} \mathrm{~s}^{-1}\end{array}$ & $\begin{array}{c}\beta_{2,0}, \\
10^{-10} \mathrm{~m} \mathrm{~s}^{-1}\end{array}$ & $\begin{array}{c}\alpha_{1,0} \\
10^{-9} \mathrm{~mol} \mathrm{~m}^{-2} \mathrm{~s}^{-1}\end{array}$ & $\begin{array}{c}\alpha_{2,0}, \\
10^{-10} \mathrm{~mol} \mathrm{~m}^{-2} \mathrm{~s}^{-1}\end{array}$ & $\mathbf{a}_{1} / \mathbf{a}_{2}$ & $\mathrm{~d}_{1} / \mathrm{d}_{2}$ & $\begin{array}{c}\mathrm{E}_{\prime} \\
\mathrm{m} \mathrm{mN^{-1 }}\end{array}$ \\
\hline 25 & 2.5 & 3.0 & 5.6 & 0.88 & 7.0 & 1.6 & $0.7 / 1 / 2$ & $0.3 / 1.0$ & 0.0025 \\
\hline 50 & 7.0 & 3.0 & 1.6 & 2.0 & 3.0 & 8.0 & $0.5 / 0.3$ & $0.4 / 1.0$ & 0.00304 \\
\hline
\end{tabular}

Figure 3 illustrates the theoretical dependence of the adsorption dynamics of heptane at a water drop surface. Similar to the curves shown in Figure 2, these curves exhibit two characteristic points, which are especially evident at $20^{\circ} \mathrm{C}$. Figure 3 also shows the experimental data for $25^{\circ} \mathrm{C}$ reported in [6], where the X-ray and neutron reflection methods were used to determine the adsorbed amount of deuterated heptane. Note that the data for the heptane adsorption layer thickness given in [6] in Angstroms were recalculated here onto the adsorbed heptane mass assuming the value $0.7 \mathrm{~kg} \mathrm{dm}^{-3}$ for the density of liquid heptane. Again, the agreement between the experimental data [6] and the proposed theory is acceptable.

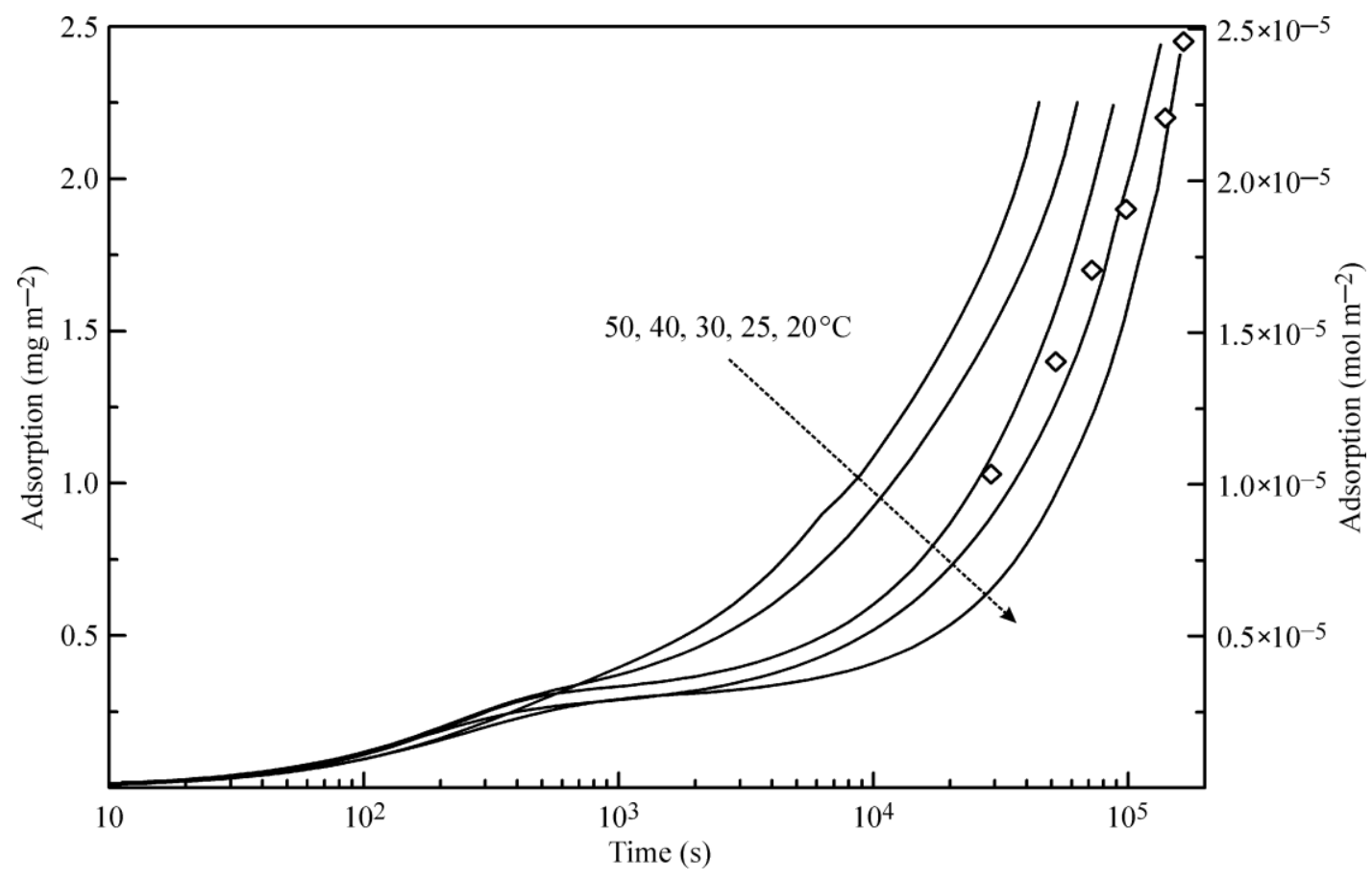

Figure 3. The dynamics of heptane adsorption on water drop surface at various temperatures: curves, theoretical calculations based on the proposed model; points, experimental data obtained in [6]. For detailed explanation, see text.

Figures 4 and 5 illustrate the coverages of the five layers at 20 and $50{ }^{\circ} \mathrm{C}$, respectively. It is seen that, for Layers 2-5, the increase of temperature leads to an increase of coverages, and the difference in 
the times necessary to attain a certain coverage become shorter. In addition, the coverages of Layers $2-5$ are quite high, despite the relatively low $b_{2}$ values. We attribute this to the mutual influence of adjacent layers and, in particular, to a decreased desorption rate due to the screening of lower layers by subsequent layers.

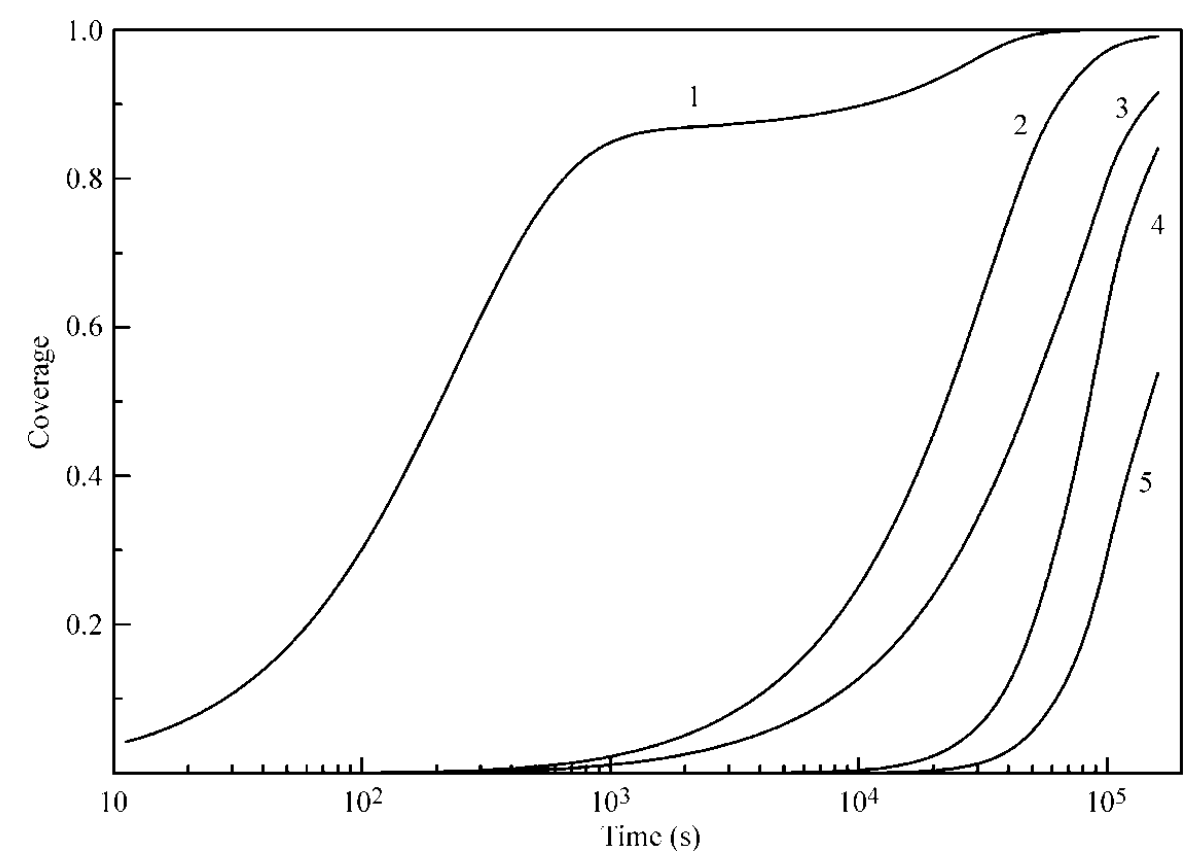

Figure 4. Time dependence of the coverage for each of the five adsorbed layers at $20^{\circ} \mathrm{C}$.

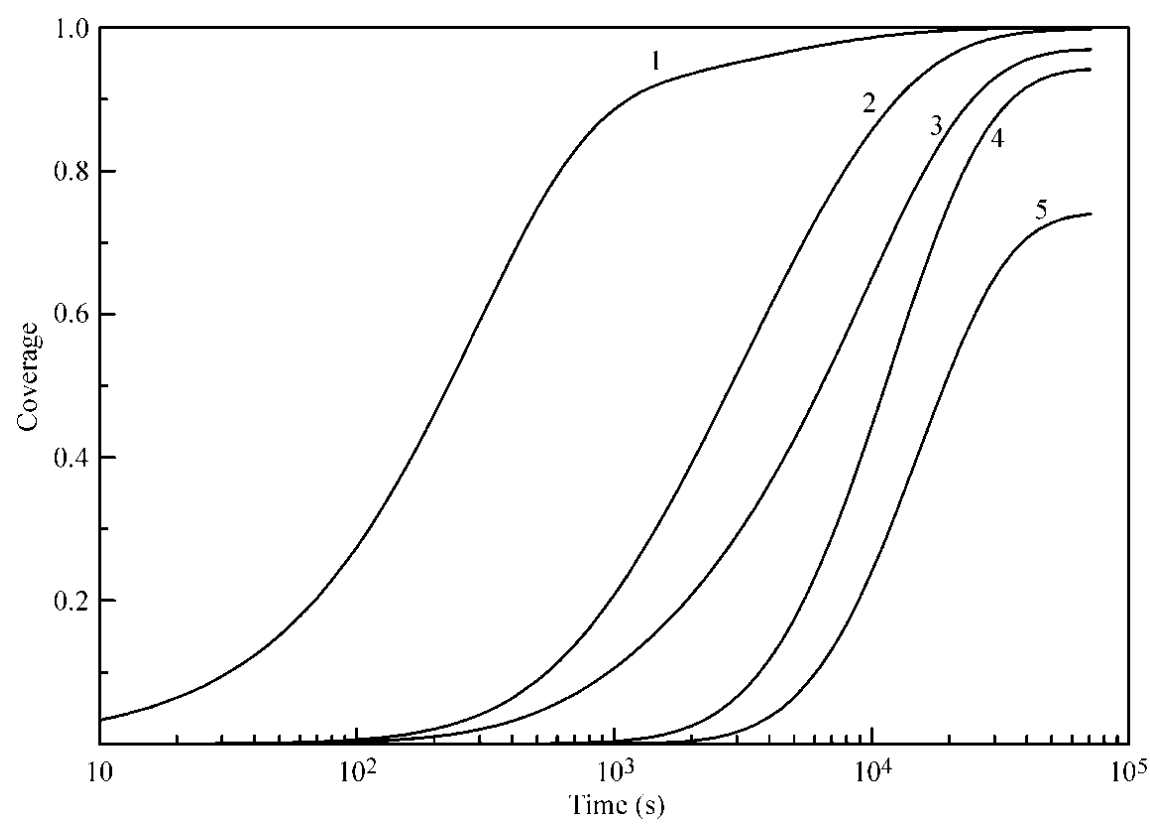

Figure 5. Time dependence of the coverage for each of the five adsorbed layers at $50{ }^{\circ} \mathrm{C}$.

The effect of the intrinsic compressibility is quite essential. For example, the calculations for $30^{\circ} \mathrm{C}$ and a compressibility coefficient $\varepsilon=0.0023 \mathrm{~m} \mathrm{mN}^{-1}$ yield different total adsorption values for the same time of 80,000 s and systems in which different numbers of layers $\mathrm{L}$ are assumed: $0.33 \times 10^{-5}$, $0.7 \times 10^{-5}, 1.1 \times 10^{-5}, 1.65 \times 10^{-5}$ and $2.16 \times 10^{-5} \mathrm{~mol} \mathrm{~m}^{-2}$ for $\mathrm{L}=1,2,3,4$, and 5 , respectively. That is, the increasing number of adsorbed layers in the model system results in an increase of the adsorbed 
amount in each layer; in particular, for the five-layer model, the adsorbed amount per each layer is $0.44 \times 10^{-5} \mathrm{~mol} \mathrm{~m}^{-2}$. This phenomenon is due to the compressibility effect, i.e., the decrease of the heptane molar area with the increase in surface pressure, cf. Equation (10). Note, however, that a decrease in molar area is accompanied by a respective increase in the thickness of the adsorbed layer, so that the volume per molecule in the layer does not change significantly [22]. For incompressible adsorbed layers $(\varepsilon=0)$ and $\mathrm{L}=5$ the calculations yield the total adsorption of $1.65 \times 10^{-5} \mathrm{~mol} \mathrm{~m}^{-2}$, that is, $0.33 \times 10^{-5} \mathrm{~mol} \mathrm{~m}^{-2}$ per each adsorbed layer.

Figures 6 and 7 illustrate the influence of certain model parameters on the dynamic surface tension and adsorption kinetics, respectively. Curve 3 is reproduced in Figures 2 and 3 for $30^{\circ} \mathrm{C}$. Curve 1 was calculated for $a b_{2}$ value twice as high as $b_{2}=\beta_{2,0} / \alpha_{2,0}$ with $\beta_{2,0}$ and $\alpha_{2,0}$ listed in Table 1 . Curve 2 was calculated for $d_{2}=0$ (instead of $d_{2}=1.4$ as given in Table 1 ). Both the increase of $b_{2}$ and the decrease of the adsorption and desorption activation energies (related to $d_{2}$ ) quite expectedly result in an increased adsorption rate. Curve 4 corresponds to $a_{2}=0$ (instead of $a_{2}=1.0$ as given in Table 1 ): this corresponds to the increase of the adsorption activation energy and results in a decreased adsorption rate (note that the decrease of $\mathrm{a}_{\mathrm{i}}=\left(\varphi_{\mathrm{d}, \mathrm{i}}-\varphi_{\mathrm{a}, \mathrm{i}}\right) / 2$ corresponds to an increase of $\varphi_{\mathrm{a}, \mathrm{i}}$, i.e., to the increase of the adsorption activation energy at the same values of other parameters). Curve 5 , which was calculated for systems with only two layers instead of five, shows higher surface tension, and not only a slower kinetics, but also very low adsorption value, as was already discussed above.

In Figure 8, the time dependencies of the coverages of Layers 1, 2 and 4 at $30{ }^{\circ} \mathrm{C}$ are shown. Solid curves correspond to the values calculated with the parameters listed in Table 1, while, for the calculations shown by the dashed curve, the parameter $b_{2}$ was twice increased as compared to that in Table 1. It is essential that the increase of $b_{2}$ value not only leads to an acceleration and increase of adsorption in the second and further layers, but also enhances the adsorption in the first layer. This phenomenon, as was already mentioned above, is due to the hampering of the desorption from the first layer because of the enhanced formation of the second (and further) layers.

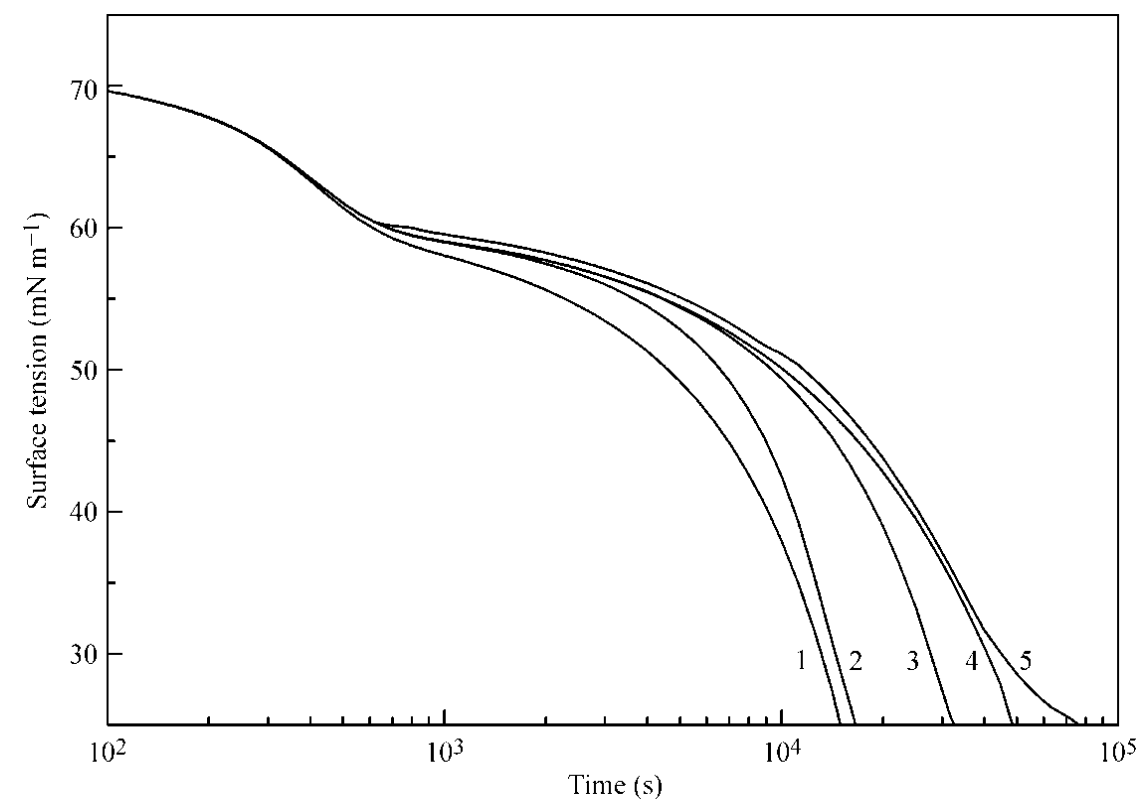

Figure 6. Influence of certain model parameters on the dynamic surface tension. For detailed discussion, see text. 


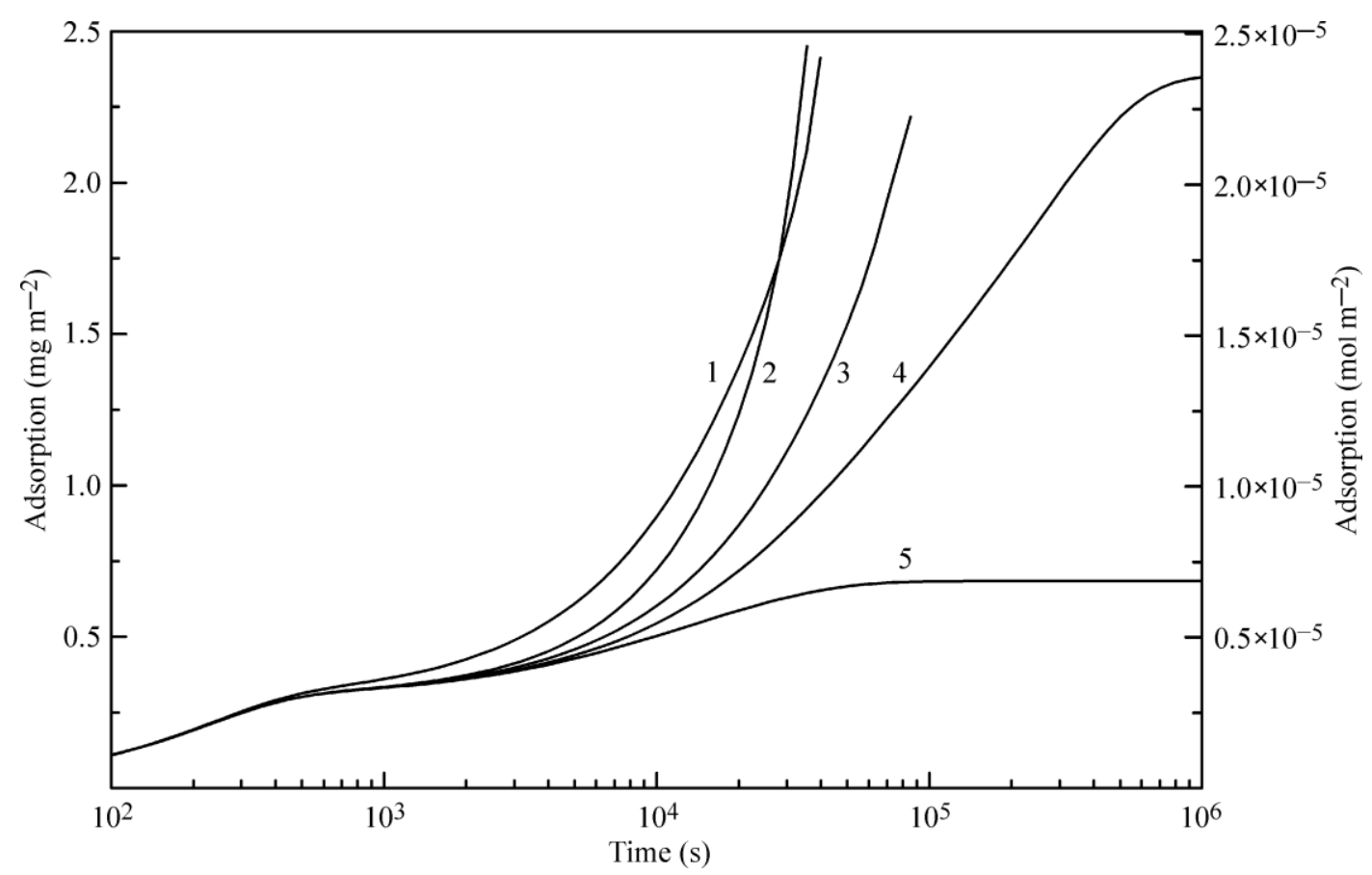

Figure 7. Influence of certain model parameters on the adsorption kinetics. For details, see text.

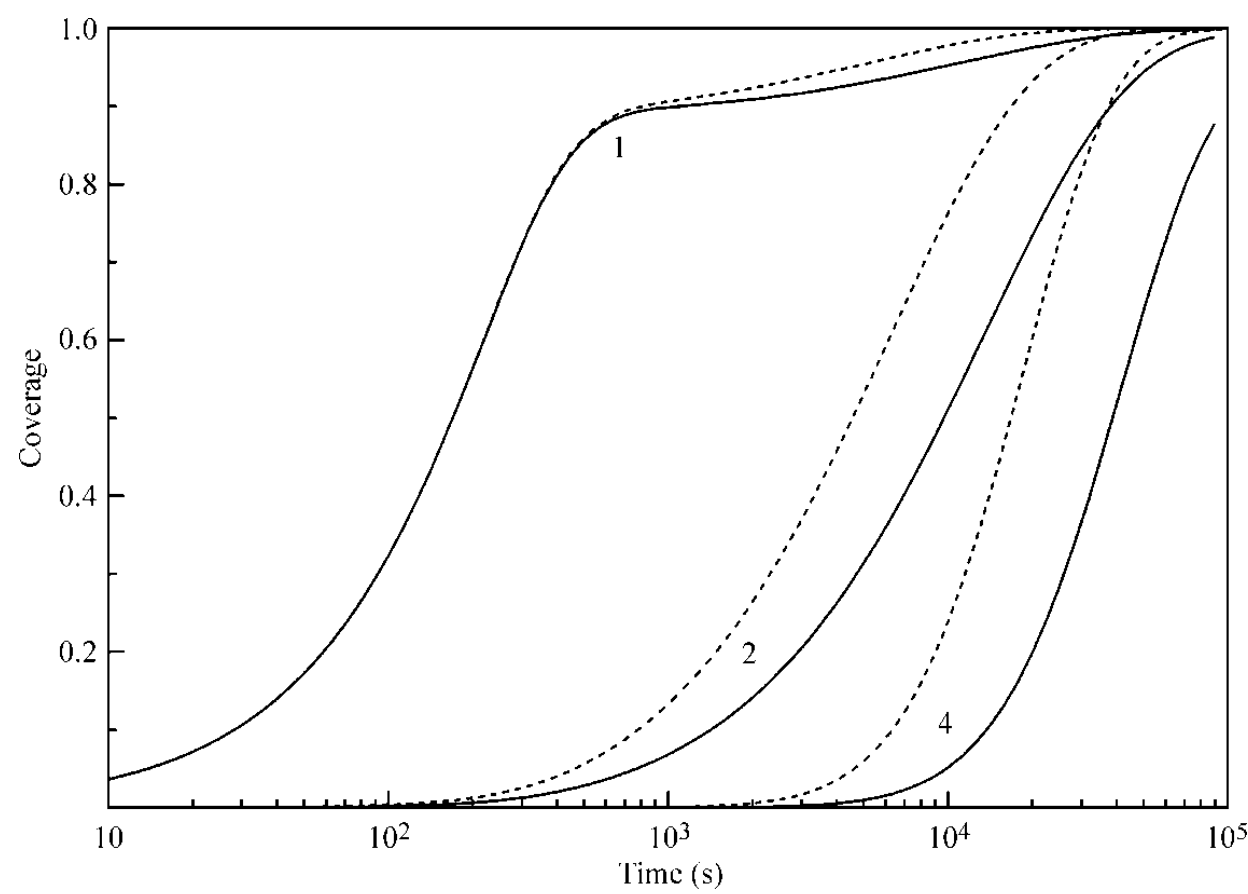

Figure 8. Dynamics of the coverage of Layers 1,2 and 4 at $30^{\circ} \mathrm{C}$ for two different $b_{2}$ values. For detailed discussion, see text.

\section{Conclusions}

Experimental data on the dynamics of multilayer adsorption of heptane from the vapor phase at the water drop surface are analyzed. Experimental dynamic surface tension of water drops in air saturated by heptane vapor shows a sharp decrease (from about $60 \mathrm{~m} \mathrm{~N} \mathrm{~m}^{-1}$ down to $30-40 \mathrm{mN} \mathrm{m}^{-1}$ ) at sufficiently long adsorption times $\left(10,000-15,000 \mathrm{~s}\right.$ at $20^{\circ} \mathrm{C}$, and $500-700 \mathrm{~s}$ at $\left.50^{\circ} \mathrm{C}\right)$. This phenomenon 
indicates the formation of heptane adsorption layers with significant thicknesses, much thicker than a monolayer. Such conclusion is confirmed by direct $\mathrm{X}$-ray and neutron reflection measurements of the adsorption film thicknesses of alkanes, according to which the maximum thickness can amount up to $4-5 \mathrm{~nm}[6]$.

For the analysis of experimental data, we proposed a model of multilayer adsorption of alkanes from the vapor phase at the water surface. Previous studies have shown that the adsorption kinetics of alkanes at the water surface is by several orders of magnitude slower than it can be expected for a diffusion controlled adsorption mechanism. Therefore, the model of adsorption proposed here basically assumes a kinetic limitation due to the existence of an energy barrier for adsorbing/desorbing molecules. The model takes into account the deceleration of desorption from the layers covered by the subsequent layers. It assumes a dependence of the adsorption and desorption kinetic coefficients on the surface coverage in the layers due to interactions between the adsorbed molecules, as well as the decrease of the molecular surface area with increasing surface pressure in the layers. Under equilibrium conditions, by neglecting the variation of the kinetic coefficients and molecular surface area, the model reduces to the classical Brunauer-Emmett-Teller (BET) adsorption isotherm [19].

The model was implemented into a computation software which was used to simulate the adsorption of heptane vapors at the surface of water drops. The calculated dependencies of adsorption and interfacial tension on time agree reasonably well with experimental data and predict a five-layer adsorption of heptane. In particular, the dynamic adsorption dependencies are found to be in good agreement with the directly measurements data [6].

Acknowledgments: The work was supported by ESA (Soft Matter Dynamics), bilateral Polish-Ukrainian project 793-46 (V.K.), and the NASU project 3-6-16:20 (E.A).

Author Contributions: R.M., V.B.F. and A.J. conceived the study; V.B.F. and V.I.K. developed the theory; V.B.F. and A.J. designed the experiments; E.V.A. developed the software; all authors participated in the writing of the paper.

Conflicts of Interest: The authors declare no conflict of interest.

\section{Appendix A}

To compose the calculation algorithm for the numerical solution of Equations (7)-(9) and Equations (10)-(13), taking into account the additional equations Equation (6), it is convenient to express the equations in terms of dimensionless quantities:

$$
\mathrm{T}=\omega_{0} \alpha_{1,0} \mathrm{t}, \mathrm{b}_{1} \mathrm{c}=\frac{\beta_{1,0}}{\alpha_{1,0}} \mathrm{c}, \mathrm{b}_{2} \mathrm{c}=\frac{\beta_{2,0}}{\alpha_{1,0}} \mathrm{c}, \delta_{\alpha}=\frac{\alpha_{2,0}}{\alpha_{1,0}}, \mathrm{p}_{\mathrm{j}}=\frac{\omega_{0}}{\mathrm{RT}} \Pi_{\mathrm{j}}, \mathrm{k}=\varepsilon \frac{\mathrm{RT}}{\omega_{0}}
$$

Then the set of Equations (7)-(9) becomes:

$$
\begin{gathered}
\frac{\mathrm{d} \theta_{1}}{\mathrm{dT}}=\left(1-\kappa p_{1}\right)\left[\mathrm{b}_{1} \mathrm{c}\left(1-\theta_{1}\right) \exp \left(-\varphi_{\mathrm{a}, 1} \theta_{1}\right)-\left(\theta_{1}-\theta_{2}\right) \exp \left(-\varphi_{\mathrm{d}, 1} \theta_{1}\right)\right](j=1) \\
\frac{\mathrm{d} \theta_{\mathrm{j}}}{\mathrm{dT}}=\left(1-\kappa p_{\mathrm{j}}\right)\left[\mathrm{b}_{2} \mathrm{c}\left(\theta_{\mathrm{j}-1}-\theta_{\mathrm{j}}\right) \exp \left(-\varphi_{\mathrm{a}, 2} \theta_{\mathrm{j}}\right)-\delta_{\alpha}\left(\theta_{\mathrm{j}}-\theta_{\mathrm{j}+1}\right) \exp \left(-\varphi_{\mathrm{d}, 2} \theta_{\mathrm{j}}\right)\right](2 \leq \mathrm{j}<\mathrm{L}) \\
\frac{\mathrm{d} \theta_{\mathrm{L}}}{\mathrm{dT}}=\left(1-\kappa \mathrm{p}_{\mathrm{L}}\right)\left[\mathrm{b}_{2} \mathrm{c}\left(\theta_{\mathrm{L}-1}-\theta_{\mathrm{L}}\right) \exp \left(-\varphi_{\mathrm{a}, 2} \theta_{\mathrm{L}}\right)-\delta_{\alpha} \theta_{\mathrm{L}} \exp \left(-\varphi_{\mathrm{d}, 2} \theta_{\mathrm{L}}\right)\right](\mathrm{j}=\mathrm{L})
\end{gathered}
$$

and Equations (11) and (12) read:

$$
\begin{gathered}
\mathrm{p}_{1}\left(1-\kappa \mathrm{p}_{1}\right)=-\left[\ln \left(1-\theta_{1}\right)+\mathrm{a}_{1} \theta_{1}^{2}\right](\mathrm{j}=1) \\
\mathrm{p}_{\mathrm{j}}\left(1-\kappa \mathrm{p}_{\mathrm{j}}\right)=-\left[\ln \left(1-\theta_{\mathrm{j}} \theta_{\mathrm{j}-1}\right)+\mathrm{a}_{2} \theta_{\mathrm{j}}^{2}\right](2 \leq \mathrm{j}<\mathrm{L})
\end{gathered}
$$


Equations (A2)-(A6) constitute the set of $2 \mathrm{~L}$ equations with the unknowns $\theta_{\mathrm{j}}$ and $\mathrm{p}_{\mathrm{j}}$. One easily sees that the general form of Equations (A2)-(A4) is:

$$
\frac{d \theta_{j}}{d T}=f_{j}\left(p_{j}, \theta_{j-1}, \theta_{j}, \theta_{j+1}\right)
$$

The solution of Equation (A7) throughout a small interval $\delta T\left\{T_{1}, T_{2}\right)$ is:

$$
\left.\theta_{j}\right|_{T_{1}} ^{T_{2}}=\int_{T_{1}}^{T_{2}} f_{j}\left(p_{j}, \theta_{j-1}, \theta_{j}, \theta_{j+1}\right) d T
$$

Then expressing the derivative in the lhs in terms of the $\theta_{j}$ values at both ends of the small interval $\delta \mathrm{T}=\mathrm{T}_{2}-\mathrm{T}_{1}$, and the integral in the rhs through the integrand values at these ends, one obtains:

$$
\theta_{j}\left(T_{2}\right)-\theta_{j}\left(T_{1}\right)=\frac{1}{2} \delta T\left\{f_{j}\left[p_{j}\left(T_{1}\right), \theta_{j-1}\left(T_{1}\right), \theta_{j}\left(T_{1}\right), \theta_{j+1}\left(T_{1}\right)\right]+f_{j}\left[p_{j}\left(T_{2}\right), \theta_{j-1}\left(T_{2}\right), \theta_{j}\left(T_{2}\right), \theta_{j+1}\left(T_{2}\right)\right]\right\}
$$

which implies a sequential process: for the known values of $p_{j}$ and $\theta_{j}$ at the temporal step $T_{1}$ one should solve simultaneously L Equations (A2)-(A4) expressed as determined by Equation (A9), and L Equations (A5) and (A6), to obtain the solution at $\mathrm{T}_{2}$.

Then the set of equations to be solved consists of L Equations (A5) and (A6):

$$
\begin{gathered}
\mathrm{p}_{1}\left(1-\kappa \mathrm{p}_{1}\right)+\ln \left(1-\theta_{1}\right)+\mathrm{a}_{1} \theta_{1}^{2}=0(\mathrm{j}=1) \\
\mathrm{p}_{\mathrm{j}}\left(1-\kappa \mathrm{p}_{\mathrm{j}}\right)+\ln \left(1-\theta_{\mathrm{j}} \theta_{\mathrm{j}-1}\right)+\mathrm{a}_{2} \theta_{\mathrm{j}}^{2}=0(2 \leq \mathrm{j} \leq \mathrm{L})
\end{gathered}
$$

and L equations:

$$
\theta_{j}\left(T_{i}\right)-\theta_{j}\left(T_{i-1}\right)-\frac{1}{2} \delta T_{i}\left[f_{j}\left(T_{i-1}\right)+f_{j}\left(T_{i}\right)\right]=0(1 \leq j \leq L)
$$

where

$$
\begin{gathered}
\mathrm{f}_{1}=\left(1-\kappa p_{1}\right)\left[\mathrm{b}_{1} \mathrm{c}\left(1-\theta_{1}\right) \exp \left(-\varphi_{\mathrm{a}, 1} \theta_{1}\right)-\left(\theta_{1}-\theta_{2}\right) \exp \left(-\varphi_{\mathrm{d}, 1} \theta_{1}\right)\right](\mathrm{j}=1) \\
\mathrm{f}_{\mathrm{j}}=\left(1-\kappa \mathrm{p}_{\mathrm{j}}\right)\left[\mathrm{b}_{2} \mathrm{c}\left(\theta_{\mathrm{j}-1}-\theta_{\mathrm{j}}\right) \exp \left(-\varphi_{\mathrm{a}, 2} \theta_{\mathrm{j}}\right)-\delta_{\alpha}\left(\theta_{\mathrm{j}}-\theta_{\mathrm{j}+1}\right) \exp \left(-\varphi_{\mathrm{d}, 2} \theta_{\mathrm{j}}\right)\right](2 \leq \mathrm{j}<\mathrm{L}) \\
\mathrm{f}_{\mathrm{L}}=\left(1-\kappa \mathrm{p}_{\mathrm{L}}\right)\left[\mathrm{b}_{2} \mathrm{c}\left(\theta_{\mathrm{L}-1}-\theta_{\mathrm{L}}\right) \exp \left(-\varphi_{\mathrm{a}, 2} \theta_{\mathrm{L}}\right)-\delta_{\alpha} \theta_{\mathrm{L}} \exp \left(-\varphi_{\mathrm{d}, 2} \theta_{\mathrm{L}}\right)\right](\mathrm{j}=\mathrm{L})
\end{gathered}
$$

with initial values:

$$
\theta_{\mathrm{j}}(0)=0, \mathrm{p}_{\mathrm{j}}(0)=0
$$

Note that the L Equations (Equation (A12)) are "recursive", i.e., the values $f_{j}\left(T_{i}+\delta T_{i}\right)$, obtained at the (i)-th temporal step are involved as constants at the next $(i+1)$-th step.

For a monolayer system $(\mathrm{L}=1)$ two equations should be simultaneously solved: Equation (A12) with:

$$
\mathrm{f}_{1}=\left(1-\kappa \mathrm{p}_{1}\right)\left[\mathrm{b}_{1} \mathrm{c}\left(1-\theta_{1}\right) \exp \left(-\varphi_{\mathrm{a}, 1} \theta_{1}\right)-\theta_{1} \exp \left(-\varphi_{\mathrm{d}, 1} \theta_{1}\right)\right]
$$

and Equation (A10). Note that neglecting the dependence of kinetic coefficients on the surface coverage $\left(\varphi_{\mathrm{a}, 1}=\varphi_{\mathrm{d}, 1}=0\right)$ and the dependence of molar area on surface pressure $(\varepsilon=0)$ one reduces the set to a single equation:

$$
\frac{1}{\omega_{0}} \frac{\mathrm{d} \theta_{1}}{\mathrm{dt}}=\beta_{1} \mathrm{c}\left(1-\theta_{1}\right)-\alpha_{1} \theta_{1}
$$

which allows for an analytical solution and describes the kinetics for the Langmuir model. 
The total surface pressure is calculated as:

$$
\Pi=\sum_{j=1}^{L} \Pi_{j}=\frac{R T}{\varpi_{0}} \sum_{j=1}^{L} p_{j}
$$

which yields the surface tension value:

$$
\gamma=\gamma_{0}-\Pi
$$

where $\gamma_{0}$ is the surface tension of the water/air surface. The total adsorption $\Gamma\left[\mathrm{mol} \mathrm{m}^{-2}\right]$ is calculated via the coverages of all $\mathrm{L}$ layers:

$$
\Gamma=\sum_{j=1}^{L} \frac{\theta_{j}}{\omega_{j}}=\frac{1}{\omega_{0}} \sum_{j=1}^{L} \frac{\theta_{j}}{1-\kappa p_{j}}
$$

For the calculations, the procedure of the Newton method with numerical calculation of Hessian described in [23] was used. The integration was performed along the non-equidistant (expanding) set of temporal nodes:

$$
\mathrm{T}_{\mathrm{i}}=\sum_{\mathrm{k}=1}^{\mathrm{i}} \delta \mathrm{T}_{\mathrm{k}}, \delta \mathrm{T}_{\mathrm{k}}=\mathrm{dT}(1+\tau)^{\mathrm{k}-1}, \mathrm{i}=1,2, \ldots
$$

with the initial values at $\mathrm{T}=0$ as in Equation (A16). The trial values (initial guesses for the Newton procedure) at the first temporal node ( $\mathrm{i}=1)$ were taken as follows: $\theta_{1}$ equal to the value obtained from Equation (A18); $\theta_{j}=d_{\text {init }} \times \theta_{j-1}(j=2, \ldots, L) ; p_{j}=\theta_{j},(j=1, \ldots, L)$. At subsequent nodes the linear extrapolation through the previous two nodes was used to obtain the initial guess. Other controlling parameters of the calculations, Equation (A22), were the initial temporal step dT and $\tau$. The convergence of the procedure was verified by: (i) the comparison of the numerical solution values for $\mathrm{L}=1, \varphi_{\mathrm{a}, 1}=\varphi_{\mathrm{d}, 1}=0, \varepsilon=0$, with those calculated by the analytical solution of Equation (A18); and (ii) the comparison of the data obtained by the numerical procedure for the values of controlling parameters differing by a factor of 10. It was found that throughout the relevant domain of calculation parameters the solutions obtained with $\mathrm{dT}=0.0001$ and $\tau=0.002$ were consistent to within the 6-th decimal place, and the value $d_{\text {init }}=0.1$ ensured the convergence of the initial approximation at the first temporal node.

\section{References}

1. Lou, A.J.; Pethica, B.A. Adsorption of hexane at the water/vapor interface. Langmuir 1997, 13, 4933-4934. [CrossRef]

2. Pethica, B.A.; Glasser, M.L.; Cong, E.H. Intermolecular forces between the $n$-alkanes methane to butane adsorbed at the water/vapor interface. Langmuir 2003, 19, 6820-6825. [CrossRef]

3. Ashbaugh, H.S.; Pethica, B.A. Alkane adsorption at the water-vapor interface. Langmuir 2003, 19, 7638-7645. [CrossRef]

4. Pethica, B.A.; Glasser, M.L. Lateral intermolecular forces in the physisorbed state: Surface field polarization of benzene and $n$-hexane at the water/and Mercury/vapor interfaces. Langmuir 2005, 21, 944-949. [CrossRef] [PubMed]

5. Schlossman, M.L. Liquid-liquid interfaces: Studied by X-ray and neutron scattering. Curr. Opin. Colloid Interface Sci. 2002, 7, 235-243. [CrossRef]

6. Kwon, O.S.; Jing, H.; Shin, K.; Wang, X.; Satija, S.K. Formation of $n$-alkane layers at the vapor/water interface. Langmuir 2007, 23, 12249-12253. [CrossRef] [PubMed]

7. Javadi, A.; Moradi, N.; Möhwald, H.; Miller, R. Adsorption of alkanes from the vapor phase on water drops measured by drop profile analysis tensiometry. Soft Matter 2010, 6, 4710-4714. [CrossRef]

8. Fainerman, V.B.; Aksenenko, E.V.; Kovalchuk, V.I.; Javadi, A.; Miller, R. Study of the co-adsorption of hexane from the gas phase at the surface of aqueous $\mathrm{C}_{10} \mathrm{EO}_{8}$ drops. Soft Matter 2011, 7, 7860-7865. [CrossRef] 
9. Javadi, A.; Moradi, N.; Fainerman, V.B.; Möhwald, H.; Miller, R. Alkane vapor and surfactants co-adsorption on aqueous solution interfaces. Colloids Surf. A 2011, 391, 19-24. [CrossRef]

10. Mucic, N.; Moradi, N.; Javadi, A.; Aksenenko, E.V.; Fainerman, V.B.; Miller, R. Mixed adsorption layers at the aqueous CnTAB solution/hexane vapor interface. Colloids Surf. A 2014, 442, 50-55. [CrossRef]

11. Mucic, N.; Moradi, N.; Javadi, A.; Aksenenko, E.V.; Fainerman, V.B.; Miller, R. Effect of partial vapor pressure on the co-adsorption of surfactants and hexane at the water/hexane vapor interface. Colloids Surf. A 2015, 480, 79-84. [CrossRef]

12. Mys, V.D.; Fainerman, V.B.; Makievski, A.V.; Krafft, M.P.; Miller, R. Dynamic surface tension of $\mathrm{C}_{10} \mathrm{EO}_{8}$ at the aqueous solution/hexane vapor interface as measured by bubble pressure tensiometry. Colloids Surf. A 2015, 483, 137-141. [CrossRef]

13. Krafft, M.P.; Fainerman, V.B.; Miller, R. Modeling of the effect of fluorocarbon gases on the properties of phospholipid monolayers and the adsorption dynamics of their aqueous solutions or dispersions. Colloid Polymer Sci. 2015, 293, 3091-3097. [CrossRef]

14. Miller, R.; Aksenenko, E.V.; Kovalchuk, V.I.; Trukhin, D.V.; Tarasevich, Y.I.; Fainerman, V.B. Mixed protein/hexane adsorption layers formed at the surface of protein solution drops surrounded by hexane vapor. Adv. Mater. Interfaces 2017, 4. [CrossRef]

15. Fainerman, V.B.; Aksenenko, E.V.; Miller, R. Influence of alkane and perfluorocarbons vapors on adsorbed surface layers and spread insoluble monolayers of surfactants, proteins and lipids. Adv. Colloid Interface Sci. 2017, 244, 100-112. [CrossRef] [PubMed]

16. Fainerman, V.B.; Aksenenko, E.V.; Kovalchuk, V.I.; Miller, R. Surface tension of water and $\mathrm{C}_{10} \mathrm{EO}_{8}$ solutions at the interface to hexane saturated air. Colloids Surf. A 2016, 505, 118-123. [CrossRef]

17. Miller, R.; Aksenenko, E.V.; Kovalchuk, V.I.; Fainerman, V.B. Adsorption of $\mathrm{C}_{14} \mathrm{EO}_{8}$ at the interface between its aqueous solution drop and air saturated by different alkanes vapor. Phys. Chem. Chem. Phys. 2017, 19, 2193-2200. [CrossRef] [PubMed]

18. Kairaliyeva, T.; Fainerman, V.B.; Aksenenko, E.V.; Kovalchuk, V.I.; Tarasevich, Y.I.; Miller, R. Adsorption of alkane vapor at water drop surfaces. Colloids Surf. A 2017, 532, 541-547. [CrossRef]

19. Brunauer, S.; Emmett, P.H.; Teller, E. Adsorption of gases in multimolecular layers. J. Am. Chem. Soc. 1938, 60, 309-319. [CrossRef]

20. Fainerman, V.B.; Lucassen-Reynders, E.H. Adsorption of single and mixed ionic surfactants at fluid interfaces. Adv. Colloid Interface Sci. 2002, 96, 295-323. [CrossRef]

21. Fainerman, V.B.; Kovalchuk, V.I.; Aksenenko, E.V.; Michel, M.; Leser, M.E.; Miller, R. Models of two-dimensional solution assuming the internal compressibility of adsorbed molecules: A comparative analysis. J. Phys. Chem. B 2004, 108, 13700-13705. [CrossRef]

22. Fainerman, V.B.; Miller, R.; Kovalchuk, V.I. Influence of the compressibility of adsorbed layers on the surface dilational elasticity. Langmuir 2002, 18, 7748-7752. [CrossRef]

23. Press, W.H.; Teukolsky, S.A.; Vetterling, W.T.; Flannery, B.P. Numerical Recipes, 3rd ed.; Cambridge University Press: Cambridge, UK, 2007; ISBN 978-0-521-88068-8.

(c) 2017 by the authors. Licensee MDPI, Basel, Switzerland. This article is an open access article distributed under the terms and conditions of the Creative Commons Attribution (CC BY) license (http:/ / creativecommons.org/licenses/by/4.0/). 